\title{
Phylogeny of Oral Asaccharolytic Eubacterium Species Determined by 16 S Ribosomal DNA Sequence Comparison and Proposal of Eubacterium infirmum sp. nov. and Eubacterium tardum sp. nov.
}

\author{
SARAH L. CHEESEMAN, ${ }^{1}$ SARAH J. HIOM, ${ }^{2}$ ANDREW J. WEIGHTMAN,${ }^{3}$ AND WILLIAM G. WADE ${ }^{2 *}$ \\ Department of Periodontology, University of Wales College of Medicine, ${ }^{1}$ and School of Pure and Applied Biology, \\ University of Wales College of Cardiff, ${ }^{3}$ Cardiff, and Department of Oral and Dental Science, University of Bristol, \\ Bristol, ${ }^{2}$ United Kingdom
}

\begin{abstract}
16S rRNA gene sequences of Eubacterium brachy, Eubacterium nodatum, Eubacterium saphenum, Eubacterium timidum, and two previously unnamed taxa were determined. The results of a phylogenetic analysis indicated that all of the strains sequenced belonged to a deep branch of the low-G + C-content gram-positive group. The levels of $16 \mathrm{~S}$ ribosomal DNA sequence similarity between species were low, suggesting that a number of genera may be represented in this group. The representatives of the two unnamed taxa, which were isolated from patients with periodontitis, were clearly distinct from the previously described species, and, therefore, the following two new species are proposed: Eubacterium infirmum (type strain, NCTC 12940) and Eubacterium tardum (type strain, NCTC 12941).
\end{abstract}

The oral asaccharolytic Eubacterium species are a group of gram-positive anaerobic bacilli which have been found in numbers in patients with periodontal disease and other oral infections, but are only rarely detected at healthy oral sites $(8,10$, 13-15, 19, 20, 24, 26). Four species, Eubacterium brachy, Eubacterium nodatum, Eubacterium saphenum, and Eubacterium timidum, have been described previously $(9,21)$, although several unnamed taxa have also been reported $(4,13-15,18,22$, 23). Historically, the genus Eubacterium has been a genus of convenience and a repository for a collection of diverse organisms that do not correspond to the descriptions of other genera. Therefore, there is considerable heterogeneity among the species placed in this genus. This fact was confirmed for oral Eubacterium species by the results of a recent DNA homology study in which negligible levels of DNA homology between species were observed (16). Phylogenetic analyses of $16 \mathrm{~S}$ rRNA sequences have revealed that many Eubacterium species are closely related to members of the genus Clostridium and that Eubacterium species are widely distributed among the taxa of low-G + C-content gram-positive bacteria (5).

The aim of this study was to use $16 \mathrm{~S}$ rRNA sequencing to construct a phylogeny for the oral asaccharolytic Eubacterium species.

\section{MATERIALS AND METHODS}

Eubacterium brachy ATCC $33089^{\mathrm{T}}$ ( $\mathrm{T}=$ type strain), Eubacterium nodatum ATCC $33099^{\mathrm{T}}$, Eubacterium saphenum ATCC $49989^{\mathrm{T}}$, and Eubacterium timidum ATCC $33093^{\mathrm{T}}$ were obtained from the American Type Culture Collection. Strain W1471, a representative of the unnamed taxon cluster 1 (23), and strain $87 \mathrm{~K}$, a representative of the taxon New 1 (4), had been previously isolated from patients with periodontitis.

A metabolic end product analysis was performed as described previously (23). Enzyme profiles were generated with a Rapid ID32A kit (BioMerieux) according to the manufacturer's instructions. Biochemical tests were performed by standard methods as described previously (22).

Genomic DNA was isolated as follows (1). Bacterial cells were harvested from

* Corresponding author. Present address: Department of Oral Medicine and Pathology, Floor 28, Guy's Tower, Guy's Hospital, London Bridge, London, SE1 9RT, United Kingdom. Phone: 44171 955 2849. Fax: 44171955 2847. Electronic mail address: W.Wade @umds.ac.uk. two plates containing Fastidious Anaerobe Agar (LabM) supplemented with 5\% sheep blood following $96 \mathrm{~h}$ of anaerobic incubation and were suspended in 310 $\mu \mathrm{l}$ of HTE buffer $(50 \mathrm{mM}$ Tris $\mathrm{HCl}, 20 \mathrm{mM}$ disodium EDTA; $\mathrm{pH}$ 8). The resulting suspension was incubated at $-70^{\circ} \mathrm{C}$ overnight and then snap-thawed at $50^{\circ} \mathrm{C}$. Then $350 \mu \mathrm{l}$ of HTE buffer containing $2 \%$ (vol/ $/ \mathrm{vol}$ ) sarcosyl was added, and the preparation was vortex mixed. A 5- $\mu$ l portion of RNase was added, and the solution was incubated at $37^{\circ} \mathrm{C}$ for $15 \mathrm{~min} ; 100 \mu \mathrm{l}$ of a $10-\mathrm{mg} / \mathrm{ml}$ proteinase $\mathrm{K}$ solution in TNE $(10 \mathrm{mM}$ Tris $\mathrm{HCl}, 10 \mathrm{mM} \mathrm{NaCl}, 0.1 \mathrm{mM}$ disodium EDTA; $\mathrm{pH}$ 8 ) was added, and the preparation was incubated at $50^{\circ} \mathrm{C}$ for $90 \mathrm{~min}$. Then $85 \mu \mathrm{l}$ of a solution containing $100 \mathrm{mg}$ of hexadecyltrimethylammonium bromide per $\mathrm{ml}$ and $51.25 \mathrm{mg}$ of $\mathrm{NaCl}$ per $\mathrm{ml}$ was added; the resulting solution was vortex mixed and incubated at $65^{\circ} \mathrm{C}$ for $20 \mathrm{~min}$. An equal volume of chloroform was added, and the mixture was centrifuged at $13,000 \times g$ for $12 \mathrm{~min}$. The top layer was removed and added to $600 \mu \mathrm{l}$ of isopropanol, and the resulting preparation was incubated overnight at $-20^{\circ} \mathrm{C}$. The DNA was pelleted by centrifugation at $13,000 \times g$ for $12 \mathrm{~min}$, washed in $80 \%$ isopropanol, air dried, resuspended in 200 $\mu \mathrm{l}$ of sterile distilled water, and stored at $-20^{\circ} \mathrm{C}$. The $16 \mathrm{~S}$ rRNA gene was amplified by PCR with different combinations of eubacterial conserved primers 27F, 1392R, and 1492R (11). The PCR were performed with Taq polymerase (Boehringer Mannheim) according to the manufacturer's instructions, except that $2 \mathrm{mM} \mathrm{MgCl} 2$ was used. The PCR products were cloned with a TA cloning kit (InVitrogen) according to the manufacturer's instructions. Plasmids were prepared for sequencing by using Magic miniprep plasmid DNA isolation kits (Promega) according to the manufacturer's instructions. Sequencing was performed with an ALF automated sequencer (Pharmacia LKB) according to the manufacturer's instructions.

The sequences which we determined were connected by using DNASIS (Hitachi) and were aligned with each other and with the sequences of related species by using Clustal V (7). Further analysis was performed by using the PHYLIP suite of programs (6). Specifically, DNADIST was used to compare sequences by the Jukes-Cantor algorithm, and NEIGHBOR was used for a neighbor-joining cluster analysis.

Estimation of $\mathbf{G}+\mathbf{C}$ content. The bacteria were grown in brain heart infusion medium (Lab M) supplemented with $0.2 \%$ arginine. The cells were harvested by centrifugation and then suspended in a solution containing $12.5 \mathrm{ml}$ of $0.15 \mathrm{M}$ sodium chloride- $50 \mathrm{mM}$ disodium EDTA per $\mathrm{g}$ of cell pellet supplemented with $5 \mathrm{mg}$ of proteinase $\mathrm{K}$ at $37^{\circ} \mathrm{C}$ for $1 \mathrm{~h}$. After 0.1 volume of $20 \%$ (wt/vol) sodium dodecyl sulfate was added and the preparation was incubated for $1 \mathrm{~h}$ at $37^{\circ} \mathrm{C}$, phenol, phenol-chloroform, and chloroform extractions were performed, and the DNA was then precipitated with ethanol. The DNA pellets were washed in $70 \%$ ethanol, resuspended in $0.1 \times \mathrm{SSC}(1 \times \mathrm{SSC}$ is $0.15 \mathrm{M} \mathrm{NaCl}$ plus $15 \mathrm{mM}$ sodium citrate $[\mathrm{pH} 7])$, and dialyzed against $0.1 \times \mathrm{SSC}$ overnight.

DNA thermal melting points were determined by using a temperature-programmable spectrophometer (2), and the $\mathrm{G}+\mathrm{C}$ contents were calculated by using standard methods (17).

Nucleotide sequence accession numbers. The nucleotide sequences determined in this study have been deposited in the EMBL database under the following accession numbers: Eubacterium timidum ATCC $33093^{\mathrm{T}}$, U13042; Eubacterium brachy ATCC 33089 , U13038; Eubacterium nodatum ATCC $33099^{\mathrm{T}}$, 
U13041; Eubacterium saphenum ATCC 49989 ${ }^{\mathrm{T}}$, U65987; Eubacterium infirmum, U13039; and Eubacterium tardum, U13037.

\section{RESULTS AND DISCUSSION}

16S rRNA genes were successfully amplified by PCR with DNAs extracted from five of the six strains studied by using primers $27 \mathrm{~F}$ and $1492 \mathrm{R}$. No product was obtained with these primers for Eubacterium nodatum ATCC $33099^{\mathrm{T}}$; however, when primers $27 \mathrm{~F}$ and $1392 \mathrm{R}$ were used, a product was obtained.

The sequences which we determined were aligned with the sequences of related bacteria obtained from SEQNET and the Ribosomal Database Project (12). Our phylogenetic analysis was based on alignment of 1,217 bases of $16 \mathrm{~S}$ ribosomal DNA after manual editing. The following regions were included in the analysis (Escherichia coli numbering [3]): positions 28 to 68,110 to 837,851 to 1006,1045 to 1129 , and 1146 to 1391 . Some short $(<10$-base) sections in these regions where the alignment was poor were omitted from the analysis. The levels of sequence similarity were less than $94 \%$ in all pairwise comparisons of the strains whose sequences were determined in this study. Eubacterium nodatum and Eubacterium tardum were the most similar (level of sequence similarity, 93.6\%), while Eubacterium nodatum and Eubacterium timidum exhibited only $85.2 \%$ similarity.

Phylogenetic analysis of the 16S rRNA gene sequences of the oral asaccharolytic Eubacterium species included in this study resulted in assignment of these organisms to a novel deep branch of the low-G + C-content gram-positive bacterial lineage (Fig. 1). The tree topology shown in Fig. 1 was confirmed by maximum-parsimony and maximum-likelihood analyses. The high bootstrap values for the branches within the cluster indicate the coherence of this group. The deeper branches linking this group with neighboring clusters were associated with lower bootstrap values, indicating that these branches should be viewed with caution. A tree constructed with the unedited sequence data had almost the same topology; all of the main lineages were the same as the lineages on the tree constructed from the edited alignment data. The species selected for comparison were representatives of the groups found in this region of the gram-positive bacteria in a recent study (5). The nearest clusters were the clusters that included Eubacterium tenue and Peptostreptococcus anaerobius (cluster XI [5]), Eubacterium limosum and Eubacterium alactolyticum (cluster XV [5]), and Peptostreptococcus micros and Peptostreptococcus asaccharolyticus (cluster XIII [5]). The 16S rRNA sequences of representatives of a number of other Eubacterium species are available from databases. None of these sequences was found in the area of the phylogenetic tree which we studied (12).

All of the levels of similarity between strains were low, which confirmed DNA homology data which showed that the species examined are not closely related (16). However, as mentioned above, the phylogenetic tree (Fig. 1) shows that the group of organisms examined in this study constitutes a new branch of low-G + C-content gram-positive bacteria which includes no previously characterized species. Therefore, there would be little practical benefit in establishing eight new genera. The members of this branch are clearly distinct from the type species of the genus Eubacterium, Eubacterium limosum. The most sensible course of action might be to propose a new genus to encompass this branch. However, a large number of unnamed taxa are related to this group (13-15). Thus, it is appropriate to delay nomenclatural changes at the genus level until these groups have been subjected to taxonomic analysis.

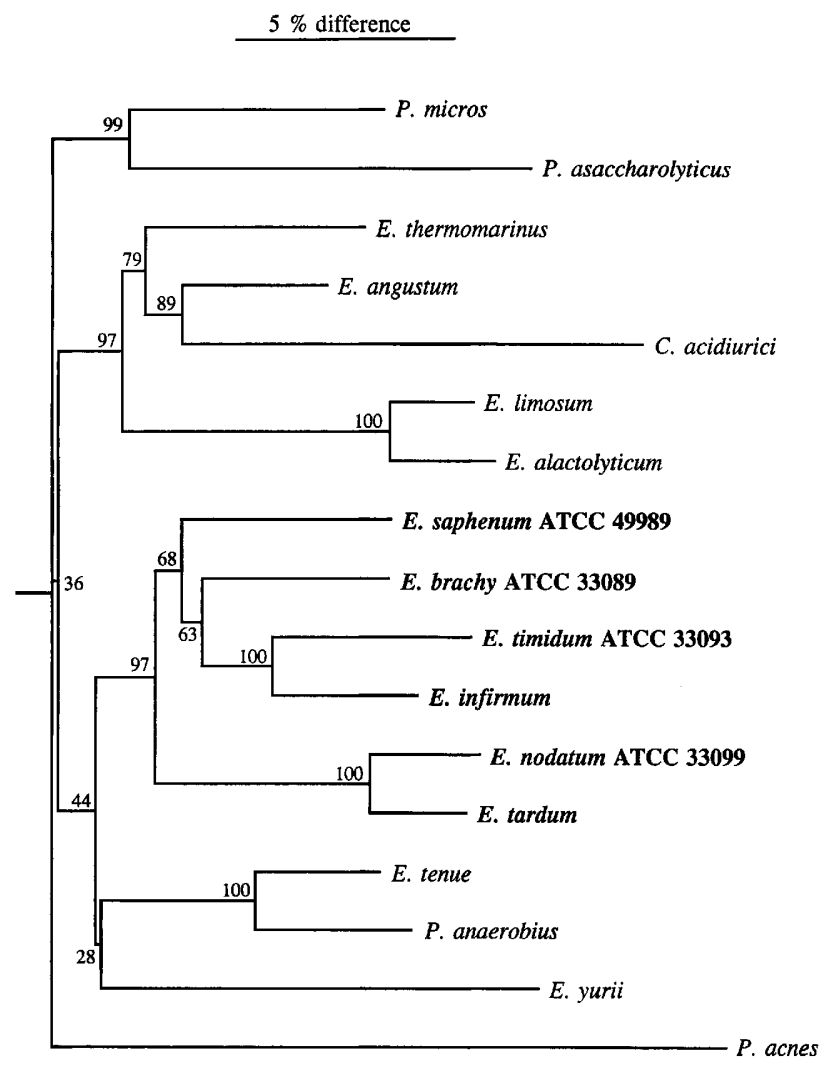

FIG. 1. Phylogenetic tree showing the relationships of oral asaccharolytic Eubacterium species and related species. The tree was constructed by using the neighbor-joining method following a distance analysis of aligned sequences and was rooted with Proprionibacterium acnes. The numbers are the bootstrap values for the branches based on data obtained for 100 trees.

The results of this study and previous studies $(4,25)$ indicate that Eubacterium cluster 1 and Eubacterium taxon New 1 are clearly distinct from previously described species and should be classified as independent species; the names proposed for these taxa are Eubacterium infirmum and Eubacterium tardum, respectively.

Useful characteristics for identifying Eubacterium infirmum, Eubacterium tardum, and related species are shown in Table 1.

Description of Eubacterium infirmum sp. nov. Eubacterium infirmum (in. fir' mum. L. adj. infirmum, delicate, referring to the delicate growth of the organism). Cells are obligately anaerobic, non-spore-forming, nonmotile, gram-positive, short rods $(0.5$ by 1.0 to $2.0 \mu \mathrm{m})$. Cells occur singly. After incubation for 7 days on Fastidious Anaerobe Agar plates, colonies are approximately $1 \mathrm{~mm}$ in diameter, circular, convex, and translucent. No hemolysis occurs on blood-containing solid media.

No acid is produced from arabinose, cellobiose, galactose, glucose, lactose, mannitol, raffinose, ribose, salicin, sucrose, or xylose. Moderate amounts of acetic and butyric acids are produced in PYG. Catalase, urease, and indole are not produced, and ammonia is not produced from arginine.

Isolated from human periodontal pockets.

The $\mathrm{G}+\mathrm{C}$ content is $38 \mathrm{~mol} \%$.

The type strain is strain NCTC 12940.

Description of Eubacterium tardum sp. nov. Eubacterium tardum (tar' dum. L. adj. tardum, slow, referring to the slow growth of the organism). Cells are obligately anaerobic, nonspore-forming, nonmotile, gram-positive, short rods ( 0.5 by 1 
TABLE 1. Differential characteristics of oral asaccharolytic Eubacterium species

\begin{tabular}{lccc}
\hline \multicolumn{1}{c}{ Species } & $\begin{array}{c}\text { Volatile fatty } \\
\text { acid(s) produced }\end{array}$ & $\begin{array}{c}\text { Rapid ID32A } \\
\text { profile }\end{array}$ & $\begin{array}{c}\text { Arginine } \\
\text { hydrolysis }\end{array}$ \\
\hline Eubacterium infirmum & a, B & 0000040000 & - \\
Eubacterium tardum & B & $0000012(0 / 4) 01$ & - \\
Eubacterium brachy & ib, iv, ic & 0000000000 & - \\
Eubacterium nodatum & a, B & 0000000000 & + \\
Eubacterium saphenum & a, b & 0000000000 & - \\
Eubacterium timidum & pa & 0000020000 & - \\
\hline
\end{tabular}

${ }^{a}$ Abbreviations: a, acetic acid; b and B, butyric acid; ib, isobutyric acid; iv, isovaleric acid; ic, isocaproic acid; pa, phenyl-acetic acid. Lowercase letters indicate minor products, and uppercase letters indicate major products.

to $3 \mu \mathrm{m})$. Cells occur singly and in diphtheroidal arrangements. No hemolysis occurs on blood-containing solid media.

No acid is produced from arabinose, cellobiose, galactose, glucose, lactose, mannitol, raffinose, ribose, salicin, sucrose, or xylose. Moderate amounts of butyric acid are produced in PYG. Catalase, urease, and indole are not produced, and ammonia is not produced from arginine.

Isolated from human periodontal pockets.

The $\mathrm{G}+\mathrm{C}$ content is $45 \mathrm{~mol} \%$.

The type strain is strain NCTC 12941.

\section{ACKNOWLEDGMENTS}

This work benefited from the use of the SEQNET facility at CCL, Daresbury Laboratory. The assistance of R. Whiley in the calculation of $\mathrm{G}+\mathrm{C}$ values is gratefully acknowledged.

\section{REFERENCES}

1. Ausubel, F. M., R. Brent, R. E. Kingston, D. D. Moore, J. G. Seidman, J. A. Smith, and K. Struhl. 1989. Current protocols in molecular biology. Greene Publishing Associates, Wiley Interscience, New York.

2. Beighton, D., H. Hayday, R. R. B. Russell, and R. A. Whiley. 1984. Streptococcus macacae sp. nov. from the dental plaque of monkeys (Macacae fuscicularis). Int. J. Syst. Bacteriol. 34:332-335.

3. Brosius, J., J. L. Palmer, H. P. Kennedy, and H. F. Noller. 1978. Complete nucleotide sequence of the 16S ribosomal RNA gene from Escherichia coli. Proc. Natl. Acad. Sci. USA 75:4801-4805.

4. Cheeseman, S. L., W. G. Wade, and A. J. Weightman. 1992. Oral asaccharolytic Eubacterium. J. Dent. Res. 71:551.

5. Collins, M. D., P. A. Lawson, A. Willems, J. J. Cordoba, J. FernandezGarayzabal, P. Garcia, J. Cai, H. Hippe, and J. A. E. Farrow. 1994. The phylogeny of the genus Clostridium: proposal of five new genera and eleven new species combinations. Int. J. Syst. Bacteriol. 44:812-826.

6. Felsenstein, J. 1993. PHYLIP (phylogeny inference package) version 3.5c Department of Genetics, University of Washington, Seattle.

7. Higgins, D. G., A. J. Bleasby, and R. Fuchs. 1992. CLUSTAL V: improved software for multiple sequence alignment. Comput. Appl. Biosci. 8:189-191.

8. Hill, G. B., O. M. Ayers, and A. P. Kohan. 1987. Characteristics and sites of infection of Eubacterium nodatum, Eubacterium timidum, Eubacterium brachy, and other asaccharolytic eubacteria. J. Clin. Microbiol. 25:15401545 .

9. Holdeman, L. V., E. P. Cato, J. A. Burmeister, and W. E. C. Moore. 1980. Descriptions of Eubacterium timidum sp. nov., Eubacterium brachy sp. nov., and Eubacterium nodatum sp. nov. isolated from human periodontitis. Int. J. Syst. Bacteriol. 30:163-169.
10. Hoshino, E. 1985. Predominant obligate anaerobes in human carious dentine. J. Dent. Res. 64:1195-1198.

11. Lane, D. J. 1991. 16S/23S rRNA sequencing, p. 115-175. In E. Stackebrandt and M. Goodfellow (ed.), Nucleic acid techniques in bacterial systematics. John Wiley \& Sons, Chichester, United Kingdom.

12. Maidak, B. L., N. Larsen, M. J. McCaughey, R. Overbeek, G. J. Olsen, K. Fogel, J. Blandy, and C. R. Woese. 1994. The Ribosomal Database Project. Nucleic Acids Res. 22:3485-3487.

13. Moore, W. E. C., L. V. Holdeman, E. P. Cato, R. M. Smibert, J. A. Burmeister, K. G. Palcanis, and R. R. Ranney. 1985. Comparative bacteriology of juvenile periodontitis. Infect. Immun. 48:507-519.

14. Moore, W. E. C., L. V. Holdeman, E. P. Cato, R. M. Smibert, J. A. Burmeister, and R. R. Ranney. 1983. Bacteriology of moderate (chronic) periodontitis in mature adult humans. Infect. Immun. 42:510-515.

15. Moore, W. E. C., L. V. Holdeman, R. M. Smibert, D. E. Hash, J. A. Burmeister, and R. R. Ranney. 1982. Bacteriology of severe periodontitis in young adults. Infect. Immun. 38:1137-1145.

16. Nakazawa, F., and E. Hoshino. 1994. Genetic relationships among Eubacterium species. Int. J. Syst. Bacteriol. 44:787-790.

17. Owen, R. J., and D. Pitcher. 1985. Current methods for estimating DNA base composition and levels of DNA-DNA hybridization, p. 67-93. In M. Goodfellow and D. E. Minnikin (ed.), Chemical methods in bacterial systematics. Academic Press, London.

18. Sato, T., E. Hoshino, H. Uematsu, and T. Noda. 1993. Predominant obligate anaerobes in necrotic pulps of human deciduous teeth. Microb. Ecol. Health Dis. 6:269-275.

19. Sundqvist, G. 1992. Associations between microbial species in dental root canal infections. Oral Microbiol. Immunol. 7:257-262.

20. Uematsu, H., and E. Hoshino. 1992. Predominant obligate anaerobes in human periodontal pockets. J. Periodontal Res. 27:15-19.

21. Uematsu, H., F. Nakazawa, T. Ikeda, and E. Hoshino. 1993. Eubacterium saphenum sp. nov., isolated from human periodontal pockets. Int. J. Syst. Bacteriol. 43:302-304.

22. Wade, W. G., A. R. Gray, E. G. Absi, and G. R. Barker. 1991. Predominant cultivable flora in pericoronitis. Oral Microbiol. Immunol. 6:310-312.

23. Wade, W. G., M. A. O. Lewis, S. L. Cheeseman, E. G. Absi, and P. A. Bishop. 1994. An unclassified Eubacterium taxon in acute dentoalveolar abscess. J. Med. Microbiol. 40:115-117.

24. Wade, W. G., J. Moran, J. R. Morgan, and M. Addy. 1992. The effects of antimicrobial acrylic strips on the subgingival microflora in chronic periodontitis. J. Clin. Periodontol. 19:127-134.

25. Wade, W. G., M. A. Slayne, and M. J. Aldred. 1990. Comparison of identification methods for asaccharolytic Eubacterium species. J. Med. Microbiol. 33:239-242.

26. Wasfy, M. O., K. T. McMahon, G. E. Minah, and W. A. Faulkner, Jr. 1992. Microbiological evaluation of periapical infections in Egypt. Oral Microbiol. Immunol. 7:100-105. 